\title{
Occupational activity and osteoarthritis of the knee
}

\author{
Cyrus Cooper, Tim McAlindon, David Coggon, Peter Egger, Paul Dieppe
}

\begin{abstract}
Objectives-To test the hypothesis that specific occupational physical activities are risk factors for knee osteoarthritis (OA).

Methods-A population-based casecontrol study of knee osteoarthritis was carried out in which 109 men and women with painful, radiographically confirmed knee OA were compared with 218 age and sex matched controls who had not suffered knee pain and had normal radiographs. Information collected included a lifetime occupational history and details of specific workplace physical activities.

Results-After adjustment for obesity and Heberden's nodes, the risk of knee $O A$ was significantly elevated in subjects whose main job entailed more than 30 minutes per day squatting (OR 6.9, 95\% CI 1.8-26.4) or kneeling (OR 3.4, 95\% CI 1.3-9.1), or climbing more than ten flights of stairs per day (OR $2 \cdot 7,95 \%$ CI $1 \cdot 2-6 \cdot 1)$. The increase in risk associated with kneeling or squatting appeared to be more marked in subjects whose jobs entailed heavy lifting, but the size of the study did not permit precise delineation of any such interaction.
\end{abstract}

Conclusions-These data suggest that prolonged or repeated knee bending is a risk factor for knee $O A$, and that risk may be higher in jobs which entail both knee bending and mechanical loading.

(Ann Rheum Dis 1994; 53: 90-93)

MRC Environmenta Epidemiology Unit, University of

Southampton,

Southampton

General Hospital,

Southampton,

United Kingdom

C Cooper

D Coggon

P Egger

The Rheumatology Unit, Bristol Royal Infirmary, Bristol, United Kingdom

T McAlindon

P Dieppe

Correspondence to: Dr C Cooper, MRC Environmental Epidemiology Unit, Epidemiology Unit, Southamplon SO9 4XY.

Accepted for publication 25 October 1993 title as an index of presumed workplace activity, rather than directly monitoring exposure to particular types of repetitive movements. Furthermore, they often have not distinguished between osteoarthritis affecting the tibiofemoral and patellofemoral compartments of the knee joint, pathologies which are known to occur independently of each other in the general population. ${ }^{8}$ We have considered these issues in a population-based case-control study of knee osteoarthritis.

\section{Method}

The study population comprised 2101 men and women aged 55 years and over, who were registered with a large general practice in Bristol. As described in an earlier report, each member of the study population was sent a postal questionnaire asking about knee pain. ${ }^{89}$ The 417 subjects who responded positively to the question: "Have you had pain in or around a knee on most days for at least a month, at some time during the past year?", were designated knee pain positive. All of these subjects and an equal number of individuals who responded negatively (knee pain negative) to this question were invited for interview and knee radiography.

Five hundred and thirteen subjects consented to radiography (273 who reported knee pain and 240 who did not). Weightbearing anteroposterior, and recumbent lateral knee radiographs were obtained on each person under standardised conditions. The three compartments of each knee (medial and lateral tibiofemoral and patellofemoral) were graded for osteoarthritis by a single observer who was unaware of the person's symptoms. Of the 273 knee pain positive subjects who had radiography, 109 had radiographic evidence of moderate or severe osteoarthritis. This was defined as changes in a tibiofemoral (TFJ) compartment graded 3 or 4 on the Kellgren and Lawrence scale ${ }^{10}$ or a grade of 3 for both joint space narrowing and osteophyte formation in a patellofemoral (PFJ) joint according to the Radiographic Atlas of Knee Osteoarthritis. ${ }^{11}$ These 109 individuals ( 30 men and 79 women) were classed as cases. Their ages ranged from 55-90 with mean $72 \cdot 7$ years.

Controls were selected from the respondents to the postal questionnaire who reported no knee pain, and who had minimal or no (Kellgren and Lawrence grades 0 or 1 ) features of osteoarthritis in either knee on $x$ ray. Two controls were selected for each case, individually matched by sex and age to within two years.

All cases and controls were interviewed by a research nurse before undergoing $x$ ray 
examination. The interviewer was thus blind to case-control status. The information sought included a lifetime occupational history with details of whether the main job entailed eight specific physical activities: squatting, kneeling, stair-climbing, heavy lifting, walking, standing, sitting, and driving. For each exposure, a definition was chosen similar to that used in previous studies of occupation and osteoarthritis. $^{12}$ In defining the main job we considered only paid employment, and excluded unpaid housework. For cases, the main job was defined as the occupation which had been held for the longest time before the onset of symptoms. For controls it was the job which had been held longest up to the date of interview. In addition, subjects' heights and weights were measured, and their hands were examined for the presence of Heberden's nodes.

Analysis was by conditional logistic regression for matched sets.

\section{Results}

The two most frequently encountered patterns of knee compartment involvement among the cases were medial tibiofemoral (24\%) and patellofemoral (32\%). Mixed medial and PFJ involvement was found in $20 \%$ of the cases, with lower frequencies of lateral $(5 \%)$, tricompartmental (7\%), lateral/PFJ (8\%) and medio-lateral (4\%) disease. The mean (SD) age at onset of knee pain was $59.9(13.0)$ years.

Osteoarthritis of the knee was strongly associated with obesity and with the presence of Heberden's nodes. Men and women in the highest third of the distribution of body mass index had a more than threefold elevation of risk compared with those in the lowest third (OR $3 \cdot 6$, 95\% CI 1·7-7·7), while those with Heberden's nodes were twice as likely to have symptomatic knee osteoarthritis (OR 2.0, 95\% CI 1·2-4.4).

Table 1 shows the associations between knee osteoarthritis and reported occupational activities after adjustment for these two potentially confounding variables. Risk was significantly elevated in subjects whose main job entailed more than 30 minutes per day of squatting (OR $6.9,95 \%$ CI $1.8-26.4$ ) or kneeling (OR $3 \cdot 4,95 \%$ CI $1 \cdot 3-9 \cdot 1$ ), or climbing more than ten flights of stairs per day

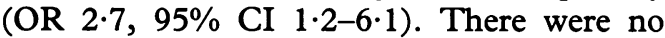

Table 1 Associations between knee osteoarthritis and reported occupational activities in main job

\begin{tabular}{|c|c|c|c|c|c|c|}
\hline \multirow[t]{2}{*}{ Occupational activity } & \multicolumn{4}{|c|}{ Numbers exposed } & \multirow{2}{*}{$\begin{array}{l}\text { Odds } \\
\text { ratio }\end{array}$} & \multirow{2}{*}{$\begin{array}{l}95 \% \\
\text { confidence } \\
\text { interval }\end{array}$} \\
\hline & $\begin{array}{l}\text { cases } \\
\text { No }\end{array}$ & $(\%)$ & $\begin{array}{l}\text { controls } \\
\text { No }\end{array}$ & (\%) & & \\
\hline $\begin{array}{l}\text { Squatting ( }>30 \mathrm{mins} / \text { day) } \\
\text { Kneeling ( }>30 \mathrm{mins} / \text { day) } \\
\text { Climbing stairs ( }>10 \text { flights/day) } \\
\text { Lifting weights over } 25 \mathrm{~kg} \\
\text { (in an average working day) }\end{array}$ & $\begin{array}{l}11 \\
13 \\
19 \\
10\end{array}$ & $\begin{array}{r}(10) \\
(12) \\
(17) \\
(9)\end{array}$ & $\begin{array}{r}4 \\
9 \\
20 \\
12\end{array}$ & $\begin{array}{l}(2) \\
(4) \\
(9) \\
(6)\end{array}$ & $\begin{array}{l}6 \cdot 9 \\
3 \cdot 4 \\
2 \cdot 7 \\
1 \cdot 4\end{array}$ & $\begin{array}{l}1 \cdot 8-26 \cdot 4 \\
1 \cdot 3-9 \cdot 1 \\
1 \cdot 2-6 \cdot 1 \\
0 \cdot 5-3 \cdot 7\end{array}$ \\
\hline $\begin{array}{l}\text { Walking ( }>2 \text { miles/day) } \\
\text { Standing ( }>2 \text { hours/day) } \\
\text { Sitting ( }>2 \text { hours/day) } \\
\text { Driving ( }>4 \text { hours/day) }\end{array}$ & $\begin{array}{r}38 \\
50 \\
47 \\
5\end{array}$ & $\begin{array}{r}(35) \\
(46) \\
(43) \\
(5)\end{array}$ & $\begin{array}{r}75 \\
99 \\
93 \\
4\end{array}$ & $\begin{array}{r}(34) \\
(45) \\
(43) \\
(2)\end{array}$ & $\begin{array}{l}0.9 \\
0 \cdot 8 \\
1 \cdot 2 \\
1 \cdot 4\end{array}$ & $\begin{array}{l}0 \cdot 5-1 \cdot 5 \\
0 \cdot 4-1 \cdot 4 \\
0 \cdot 7-2 \cdot 1 \\
0 \cdot 3-5 \cdot 8\end{array}$ \\
\hline
\end{tabular}

*Odds ratios are adjusted for body mass index (in three levels) and the presence or absence of Heberden's nodes. Each risk factor was examined independently.
Table 2 Associations of knee osteoarthritis with body mass index, Heberden's nodes and selected occupational activities

\begin{tabular}{lll}
\hline Risk factors & Odds ratio & $\begin{array}{l}95 \% \\
\text { confidence } \\
\text { interval }\end{array}$ \\
\hline Body mass index $\left(\mathrm{kg} / \mathrm{m}^{2}\right)$ & & \\
$<22 \cdot 7$ & $1 \cdot 0$ & - \\
$22 \cdot 7-25 \cdot 3$ & $1 \cdot 2$ & $0 \cdot 6-2 \cdot 6$ \\
$>25 \cdot 3$ & $3 \cdot 6$ & $1 \cdot 7-7 \cdot 5$ \\
Heberden's nodes & 1.9 & $1 \cdot 0-3 \cdot 6$ \\
Squatting (>30 mins/day) & $3 \cdot 7$ & $0 \cdot 8-16 \cdot 6$ \\
Kneeling (>30 mins/day) & $1 \cdot 8$ & $0 \cdot 6-5 \cdot 7$ \\
Climbing stairs (>10 flights/day) & $2 \cdot 0$ & $0 \cdot 8-4 \cdot 7$ \\
\hline
\end{tabular}

*Odds ratios are derived from a single regression model incorporating all of the risk factors.

significant associations with heavy lifting or with prolonged walking, standing, sitting or driving.

The jobs reported by the cases that involved squatting or kneeling included teaching and nursing in women, and steel erecting, electrical maintenance, roofing and other construction work in men. There was considerable overlap between exposure to the two activities. Thus of the 22 subjects who reported kneeling for more than 30 minutes per day, eight also reported squatting. The association of knee osteoarthritis with squatting, kneeling and stair-climbing was of similar strength in men and women.

Although there were no statistically significant differences in the association between occupational activities and TFS or PFJ OA, the risks were consistently greater for medial TFJ (kneeling OR 5.9, 95\% CI 0.6-61.3; climbing OR 7.3, 95\% CI 0.3-17.5) than for PFJ (kneeling OR $1 \cdot 6,95 \%$ CI $0 \cdot 3-7 \cdot 7$; climbing OR $0 \cdot 9$, 95\% CI $0 \cdot 2-3 \cdot 1$ ) involvement. The numbers, however, included in this subset analysis were small, leading to less precise estimates of risk.

Table 2 shows associations with squatting, kneeling and climbing stairs when they were examined together in a single regression model which also included obesity and the presence or absence of Heberden's nodes. Each activity was again associated with increased risk, but odds ratios were reduced and no longer statistically significant.

We examined the influence of heavy lifting on the risk of knee OA in subjects according to their exposure to squatting, kneeling or climbing stairs (table 3 ). When compared with those not exposed to any of these activities, the group who regularly lifted over $25 \mathrm{~kg}$ at work, as well as having to kneel, squat or climb stairs,

Table 3 Interaction between occupations involving heavy lifting and repetitive knee flexion on the risk of knee osteoarthritis

\begin{tabular}{cccc}
\hline & \multicolumn{3}{c}{ Kneeling, squatting or stair-climbing } \\
\cline { 2 - 3 } Heavy lifting & No & No & Yes \\
\cline { 3 - 4 } & Yes & $\begin{array}{c}1 \cdot 0 \\
{[\mathrm{n}=203]}\end{array}$ & $\begin{array}{c}2 \cdot 5(1 \cdot 1-5 \cdot 5) \\
{[\mathrm{n}=45]}\end{array}$ \\
\cline { 3 - 4 } & $\begin{array}{c}0 \cdot 3(0 \cdot 1-1 \cdot 6) \\
{[\mathrm{n}=9]}\end{array}$ & $\begin{array}{c}5 \cdot 4(1 \cdot 4-21 \cdot 0) \\
{[\mathrm{n}=13]}\end{array}$ \\
\hline
\end{tabular}

Figures in each cell are odds ratios with $95 \%$ confidence intervals in brackets. Square brackets provide number of subjects in each cell. Odds ratios are adjusted for body mass index and Heberden's nodes. 
Table 4 Interaction between knee injury and occupations involving repetitive knee flexion on the risk of knee osteoarthritis

Kneeling, squatting or stair-climbing

\begin{tabular}{cc|c|c|}
\multicolumn{1}{c}{} & \multicolumn{1}{c}{ No } & \multicolumn{1}{c}{ Yes } \\
\cline { 3 - 4 } Knee injury & No & $\begin{array}{c}1 \cdot 0 \\
{[\mathrm{n}=169]}\end{array}$ & $\begin{array}{c}4 \cdot 6(1 \cdot 8-11 \cdot 6) \\
{[\mathrm{n}=43]}\end{array}$ \\
\cline { 3 - 4 } & Yes & $\begin{array}{c}7 \cdot 8(3 \cdot 0-20 \cdot 2) \\
{[\mathrm{n}=39]}\end{array}$ & $\begin{array}{c}7 \cdot 6(2 \cdot 1-26 \cdot 9) \\
{[\mathrm{n}=19]}\end{array}$ \\
\cline { 3 - 4 } & &
\end{tabular}

Figures in each cell are odds ratios with $95 \%$ confidence intervals in brackets. Square brackets provide number of subjects in each cell. Odds ratios are adjusted for body mas index and Heberden's nodes.

were more than five times as likely to have knee OA( OR 5.4, 95\% CI 1·4-21·0). Those who reported regular knee flexion without lifting were only at 2.5 times greater risk. We were also able to examine the interaction between reported knee injury and occupational kneeling, squatting or stair climbing, as risk factors for osteoarthritis. Forty one cases and 12 controls reported a previous knee injury which had required immobilisation for a period of greater than one week. Table 4 shows that a history of injury acted independently of occupational knee bending as a risk factor for osteoarthritis.

\section{Discussion}

The findings of this study support the hypothesis that prolonged or repetitive bending of the knee is a cause of osteoarthritis in the joint. Regular heavy lifting at work, although not independently increasing risk, appears to augment the risks associated with kneeling and squatting.

Earlier evidence linking knee osteoarthritis with occupational kneeling and squatting comes mainly from two population-based surveys in the USA. In an analysis of crosssectional data from the HANES I study, radiographic osteoarthritis of the knee at ages 55-64 was three times more common in people whose jobs were judged likely to entail knee bending, ${ }^{5}$ and in a follow up of 1400 men and women from the Framingham study, the risk of radiographic knee osteoarthritis was highest in subjects whose earlier jobs were classed both as physically demanding and also as likely to involve bending of the knees. ${ }^{6}$ In addition, a cross-sectional survey of Finnish carpet layers who spent an estimated $42 \%$ of their working day kneeling found a prevalence of knee osteophytosis significantly higher than in a control group of house painters. ${ }^{7}$

Our study complements these earlier investigations by using a different methodology. Our case definition included symptoms and required more severe changes on $x$ ray. Moreover, unlike the American studies, ${ }^{5} 6$ we included radiographic assessment of the patellofemoral joint as well as the tibiofemoral compartments. Also, information on occupational activities was collected by direct enquiry, rather than being inferred indirectly from job title as in the American investigations. The definitions of these occupational activities were established in previous epidemiological studies of occupation and osteoarthritis, which suggested that associations were most easily detectable at the extremes of the activity spectrum. ${ }^{12}$ The prevalence of exposure among our control group was therefore relatively low - less than $10 \%$ for five of the eight activities. In theory, our method of assessing exposure might be more susceptible to recall bias, but it avoided the substantial misclassification arising from the inaccuracy of a job title as a marker for occupational activity. The specificity of our findings, with associations for kneeling, squatting and climbing stairs, but not for other occupational activities such as walking, standing, sitting or driving, argues against major recall bias. Their consistency with earlier reports constitutes strong evidence for an occupational hazard.

There are at least two mechanisms whereby repetitive knee use might increase the risk of osteoarthritis. Occupations characterised by prolonged periods of kneeling and squatting might also increase the risk of meniscal or ligamentous damage to the knee, and such lesions are known risk factors for knee osteoarthritis. $^{313}$ Alternatively, repetitive loading might directly induce cartilage loss. Our observation that the risk of osteoarthritis from occupations involving knee bending is independent of that from knee injury and meniscectomy, suggests a direct effect. However, the evidence that mechanical insults directly damage articular cartilage is inconsistent. While impact loading has a detrimental effect on cartilage in animal studies, ${ }^{14}$ repetitive impulse loads appear to stimulate chondrocytes and increase production of proteoglycans. ${ }^{15-17}$ The effects of these changes on the biomechanical properties of cartilage remain uncertain.

The clustering of occupational activities with different patterns of knee osteoarthritis also has pathophysiological implications. Although most epidemiological studies have only considered tibiofemoral (TFJ) disease, isolated patellofemoral (PFJ) osteoarthritis is not uncommon, and is a recognised cause of disability in the elderly. ${ }^{8}$ In a previous analysis, we have shown that the risk factors for isolated medial TFJ disease might differ from those for PFJ disease. ${ }^{13}$ In particular, obesity and meniscectomy appeared more strongly associated with medial TFJ involvement, while Heberden's nodes (a marker for a generalised susceptibility to osteoarthritis) showed a closer association with PFJ disease. This analysis of occupational activities suggests that repetitive knee use is also more strongly associated with medial TFJ disease. The selectivity might be explained by squatting and kneeling exposing segments of the medial articular cartilage which are not normally loaded, to excess mechanical strains. ${ }^{18}$ Alternatively, it could result from imprecision in the diagnosis of PFJ osteoarthritis. We assessed radiographic PFJ involvement using an atlas of lateral knee radiographs ${ }^{11}$ which permits grading of PFJ joint space narrowing and osteophyte (the two most reproducible features of OA on routinely 
taken lateral views ${ }^{19}$ ) on a four point scale. Alternative approaches to patellofemoral radiology, such as the use of sky-line views, are currently being investigated, although their use in epidemiological studies has not been fully validated. ${ }^{20}$

Our multivariate analysis permits estimation of the attributable proportion for various occupational exposures. The statistic indicates the proportion of cases of symptomatic knee $\mathrm{OA}$ in the population which are attributable to any particular risk factor. While extrapolation from a small study such as this to the general population must be made with caution, our data suggest that around $5 \%$ of knee OA might result from occupations involving repetitive knee use.

Our failure to demonstrate a significant overall elevation of risk from heavy lifting is perhaps surprising given the clear relation of knee osteoarthritis to obesity both in our study and in many others. ${ }^{21-23}$ This association is usually assumed to reflect the increased mechanical loading of the knees in heavy people, but it could be a consequence of metabolic abnormalities in obese individuals. Several surveys have found higher rates of knee osteoarthritis in people carrying out heavy physical work, ${ }^{24-28}$ but they have not defined occupational activities more precisely, and it is not clear what proportion of subjects would also have been exposed to knee bending. Another possibility is that an effect of heavy lifting was obscured by bias in the classification of exposure as a result of censoring the occupational histories of cases at the time their symptoms began. It seems unlikely, however, that such bias would totally obscure a strong association. Our data agree with the Framingham study, in suggesting that risk may be highest in jobs which entail both loading and bending of the knee. However, our study was small, and the question about any interaction between knee bending and mechanical loading could not be completely resolved. Nor were we able to discriminate clearly the risks from repeated flexion and extension of the knee compared with continuous flexion of the joint, or the influence of duration of exposure to these activities. Further studies are now needed to consider these issues.

This study was supported by a project grant from the Arthritis and Rheumatism Council. We are grateful to Mrs Shelagh Snow for assisting with the interviews and to Mrs Gill Strange who typed the manuscript.

1 Van Saase J L C M, Van Romunde L K J, Cats A VandenBroucke J P, Valkenburg H A. Epidemiology of osteoarthritis: Zoetermeer survey: Comparison of radiological osteoarthritis in a Dutch population with that in 10 other populations. Ann Rheum Dis 1989; 48, 271-80.

2 Felson D T, Naimark A, Anderson J J, Castelli W, Meenan R F. The prevalence of knee osteoarthritis in the elderly: The Framingham Osteoarthritis Study. Arthritis Rheum 1987; 30: 914-8.

3 Davis M A, Ettinger W H, Neuhaus J M, Cho S A, Hauck W W. The association of knee injury and obesity with unilateral and bilateral osteoarthritis of the knee. $A m \mathcal{F}$ Epidemiol 1989; 130: 278-88.

4 Felson D T. Epidemiology of hip and knee osteoarthritis. Epidemiol Reviews 1988; 10: 1-28.

5 Anderson J J, Felson D T. Factors associated with osteoarthritis of the knee in the first national health and nutrition examination survey (HANES-1). $\mathrm{Am} \mathcal{F}$ Epidemiol 1988; 128: 179-89.

6 Felson D T, Hannan M T, Naimark A, et al. Occupational physical demands, knee bending, and knee osteoarthritis: results from the Framingham Study. F Rheumatol 1991; 18: $1587-92$.

7 Kivimaki J, Riihimaki H, Haninen K. Knee disorders in carpet and floor layers and painters. Scand $\mathcal{F}$ Work Environ Health 1992; 18: 310-6.

8 McAlindon T E, Snow S, Cooper C, Dieppe P A Radiographic patterns of knee osteoarthritis in the community: The importance of the patellofemoral joint. Ann Rheum Dis 1992; 51: 844-9.

9 McAlindon T E, Cooper C, Dieppe P A. Knee pain and disability in the elderly. Br f Rheum 1992; 31: 189-92.

10 Kellgren J H, Lawrence J S. Atlas of standard radiographs: the epidemiology of chronic rheumatism, vol 2. Oxford: the epidemiology of chronic

11 Spector T D, Cooper C, Cushnaghan J, Hart D J, Dieppe P A. A radiograph atlas of knee osteoarthritis. London: Springer Verlag, 1992

12 Croft P. Cooper C, Wickham C, Coggon D. Osteoarthritis of the hip and occupational activity. Scand $\mathcal{f} W k$ Environ Health 1992; 18: 59-63.

13 Cooper C, McAlindon T, Snow S, et al. Individual risk factors for symptomatic osteoarthritis of the knee. Osteoarthritis and Cartilage 1992; 1: 16-7 (abst).

14 Radin E L, Paul I L, Rose R M. Role of mechanical factors in pathogenesis of primary osteoarthritis. Lancet 1972; 519-22.

15 Radin E L, Ehrlich M G, Chernack R, Abernethy P, Paul I L, Rose R M. Effect of repetitive impulse loading on the knee joints of rabbits. Clin Orthop 1978; 131: 288-93.

16 Gray M L, Pizzanelli A M, Grodzinsky A L, Lee R C. Mechanical and physicochemical determinants of the chondrocyte biosynthetic response. F Orthop Res 1988; 6: 777-92.

17 Kampen van G P J, Veldhuijzen J P, Kuijer R, Stadt van de $\mathrm{R}$ J, Schipper C A. Cartilage response to mechanical force in high-density chondrocyte cultures. Arthritis Rheum 1985; 28: 419-24.

18 Alexander C. Flexion angles of the knee in different resting positions and their relation to the prevalence of osteoarthritis. F Rheumatol 1991; 18: 1223-6.

19 Cooper C, Cushnaghan J, Kirwan J R, et al. Radiographic assessment of the knee joint in osteoarthritis. Ann Rheum Dis 1992; 51: 80-82.

20 Jones A C, Ledingham J, McAlindon T, et al. Radiographic assessment of patellofemoral (PF) osteoarthritis (OA) using the "sky-line" view. Brit $f$ Rheumatol 1993; 32 (Suppl 1): 139 (abst)

21 Davis M A, Ettinger W H, Neuhaus J M, Hauck W W. Sex differences in osteoarthritis of the knee: the role of obesity. Am $\mathcal{F}$ Epidemiol 1988; 127: 1019-30.

22 Felson D T, Anderson J J, Naimark A, Walker A M, Meenan R F. Obesity and knee osteoarthritis: The Framingham Study. Ann Intern Med 1988; 109: 18-24.

23 Spector T D. The fat on the joint: osteoarthritis and obesity. f Rheumatol 1990; 17: 283-4

24 Kellgren J H, Lawrence J S. Rheumatism in miners: part II. X-ray study. Br f Indust Med 1952; 9: 197-207.

25 Partridge R E H, Duthie J J R., Rheumatism in dockers and civil servants: a comparison of heavy manual and civil servants: a comparison of heavy manual and

26 Lindberg H, Montgomery F. Heavy labour and the occurrence of gonarthrosis. Clin Orthop 1987; 214: 235-6.

27 Kohatsu N D, Schurman D J. Risk factors for the development of osteoarthritis of the knee. Clin Orthop 1990; 261: 242-6.

28 Vingard E, Alfredsson L, Goldie I, Hogstedt C. Occupation and osteoarthritis of the hip and knee: a register-based cohort study. Int f Epidemiol; 20: 1025-31. 